University of Nebraska - Lincoln

DigitalCommons@University of Nebraska - Lincoln

Papers in the Earth and Atmospheric Sciences Earth and Atmospheric Sciences, Department

2013

\title{
A Gridded Reconstruction of Warm Season Precipitation for Asia Spanning the Past Half Millennium
}

\author{
Song Feng \\ University of Nebraska-Lincoln, songfeng@uark.edu \\ Q. Steven $\mathrm{Hu}$ \\ University of Nebraska-Lincoln, qhu2@unl.edu \\ Qianru Wu \\ University of Nebraska-Lincoln \\ Michael E. Mann \\ The Pennsylvania State University
}

Follow this and additional works at: https://digitalcommons.unl.edu/geosciencefacpub

Part of the Earth Sciences Commons

Feng, Song; Hu, Q. Steven; Wu, Qianru; and Mann, Michael E., "A Gridded Reconstruction of Warm Season Precipitation for Asia Spanning the Past Half Millennium" (2013). Papers in the Earth and Atmospheric Sciences. 396.

https://digitalcommons.unl.edu/geosciencefacpub/396

This Article is brought to you for free and open access by the Earth and Atmospheric Sciences, Department of at DigitalCommons@University of Nebraska - Lincoln. It has been accepted for inclusion in Papers in the Earth and Atmospheric Sciences by an authorized administrator of DigitalCommons@University of Nebraska - Lincoln. 


\title{
A Gridded Reconstruction of Warm Season Precipitation for Asia Spanning the Past Half Millennium
}

\author{
SONG FENG \\ School of Natural Resources, University of Nebraska-Lincoln, Lincoln, Nebraska \\ QI HU \\ School of Natural Resources, and Department of Earth and Atmospheric Sciences, \\ University of Nebraska-Lincoln, Lincoln, Nebraska \\ QIANRU WU \\ Department of Earth and Atmospheric Sciences, University of Nebraska-Lincoln, Lincoln, Nebraska \\ MichAEL E. MANN \\ Department of Meteorology, and Earth and Environmental Systems Institute, \\ The Pennsylvania State University, University Park, Pennsylvania
}

(Manuscript received 21 February 2012, in final form 27 August 2012)

\begin{abstract}
The authors reconstructed May-September precipitation over the Asian continent $\left(5^{\circ}-55^{\circ} \mathrm{N}, 60^{\circ}-135^{\circ} \mathrm{E}\right)$ back to $\mathrm{AD} 1470$ on the basis of tree-ring data, historical documentary records, ice core records, and the few long-term instrumental data series available in the region. They employed the method of Regularized Expectation Maximization (RegEM) and applied it to 44 subregions within the continent. Verification exercises demonstrate that the reconstruction is skillful over most of the study domain, with eastern China, India, and other regions of humid climate displaying the greatest skill. Lower reconstruction skill is observed in semiarid and arid regions, which was attributable at least in part to the scarcity of observations available for calibration/ validation. The precipitation reconstructions agree well with previous reconstructions, where they are available. The explanatory value of the reconstruction is illustrated using five historically documented severe droughts in north-central China during the past half millennium. The reconstructions both validate and provide a larger-scale context for understanding these past climate events and their relationship with the Asian summer monsoons.
\end{abstract}

\section{Introduction}

Historical data are essential to our understanding of natural climate variability and also provide a long-term context for understanding current climate trends. In Asia, many key variations in climate are tied to changes in the Asian summer monsoons that strongly influence summer precipitation and, in turn, the region's agriculture and the welfare of the mass population (e.g., Liang et al. 2006; Hu and Feng 2001; Webster et al. 1998).

Corresponding author address: Dr. Qi Hu, 707 Hardin Hall, University of Nebraska-Lincoln, Lincoln, NE 68583-0987.

E-mail: qhu2@unl.edu
Because instrumental precipitation data are only available throughout the Asian continent for the past 50-100 years (except a few longer time series in India and South Korea), we must turn to long-term reconstructions of precipitation based on proxy data to place modern trends in a longer-term perspective. Such reconstructions cannot only extend the record back in time but can also allow for an assessment of the range of natural variability of Asian summer precipitation and relationships with dynamical features of the climate, such as the Asian summer monsoons.

Spatially distributed climate-sensitive tree-ring (dendroclimatic) networks have been widely used in past reconstructions of precipitation and drought at regional 
and continental scales (e.g., Fang et al. 2010, 2011; Cook et al. 2010). Fang et al. (2010) used tree-ring data to reconstruct the two leading modes of drought in central Asia. They extended estimates of precipitation back 200 years at 26 stations in northwestern China (Fang et al. 2011). Cook et al. (2010) published Asian drought reconstructions for the past 700 years at 534 grid points based on a dataset of 327 tree-ring chronologies.

Meanwhile, large-scale climate reconstructions have been performed for many regions using multiple proxy (or multiproxy) records, which include not only tree rings but also ice cores, lake sediments, speleothems, and historical documents. The climate information contained in such multiproxy datasets is often complementary in nature, potentially allowing for a more robust climate reconstruction (Mann et al. 1998; Mann 2002; Mann et al. 2008, 2009; Jones et al. 2009).

With respect to precipitation and drought specifically, Touchan et al. (2005), Pauling et al. (2006), and Neukom et al. (2010) have each used multiproxy networks to reconstruct precipitation/drought variations in past centuries for continental regions such as Europe and southern South America. Previous proxy-based precipitation reconstructions for Asia have only been attempted for specific subregions (e.g., Yuan et al. 2003; Q.-B. Zhang et al. 2003; Fang et al. 2010, 2011; Yi et al. 2012). Yi et al. (2012), for example, combined tree-ring and documentary drought/flood information to reconstruct summer precipitation in north-central China back to AD 1470 (hereafter all years are in AD). To date, no proxy-based reconstructions of precipitation have been attempted for the whole of the Asian continent.

In this study, we reconstructed boreal warm season (May-September) precipitation for the past five centuries (1470-1999) for the Asian continent (defined as the terrestrial area between $5^{\circ}$ and $55^{\circ} \mathrm{N}$ and $60^{\circ}$ and $135^{\circ} \mathrm{E}$ ) using a multiproxy dataset. In section 2 , we describe the proxy dataset, instrumental data used for calibration and verification, and details of the reconstruction method. In section 3, we present and discuss the precipitation reconstructions. In section 4 , we compare our present precipitation reconstructions with previously published reconstructions where they overlap in space and time. We further examine the fidelity of our reconstructions by comparing them with documentary information recording and describing several extreme historical Chinese drought events. In section 5, we present the key conclusions from our study.

\section{Data and methodologies}

We sought to reconstruct boreal warm season (MaySeptember) precipitation in the region of the Asian

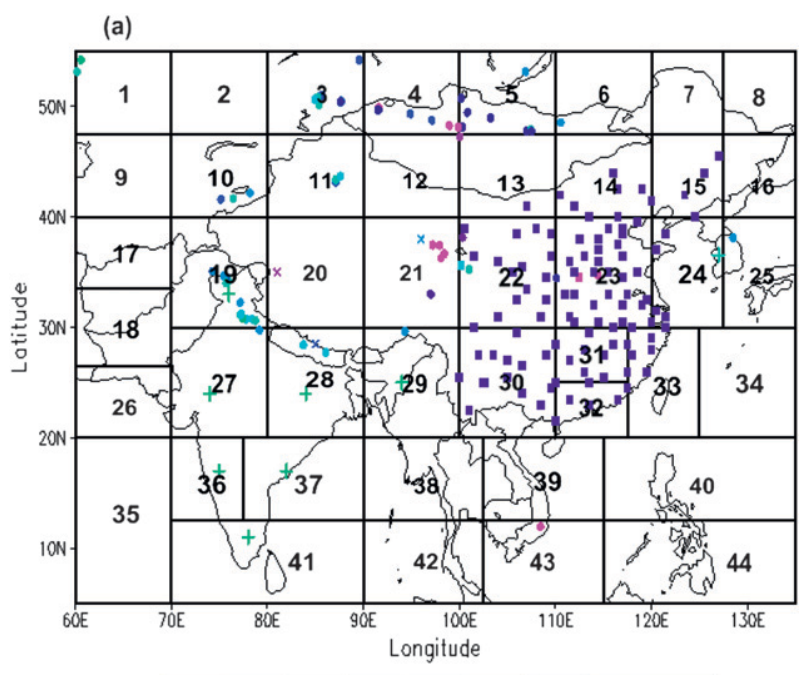

$\begin{array}{llllllllll}1350 & 1400 & 1450 & 1500 & 1550 & 1600 & 1650 & 1700 & 1750 & 1800\end{array}$

(b)

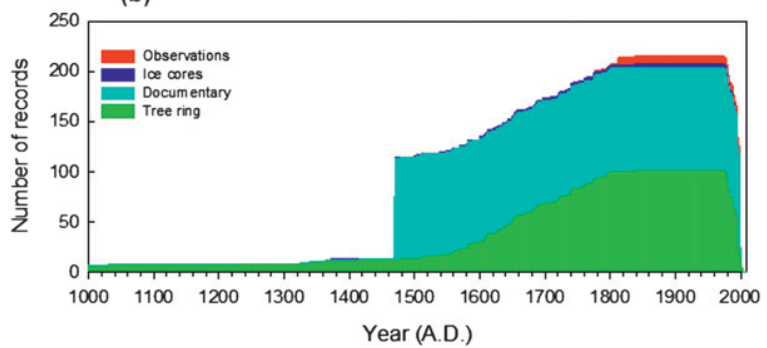

FIG. 1. (a) Spatial distribution of the proxy records used for MaySeptember precipitation reconstruction. The square, solid dot, cross, and plus signs represent the documentary, tree-ring, ice core, and nineteenth-century instrumental records, respectively. The colors of the symbols represent the started years of the proxy records. The number in the scale indicates the starting year. The study region is divided into 44 subregions (rectangles, see discussion in section 2c). (b) The temporal changes in the numbers of available proxy records in the study region.

continent between $5^{\circ}$ and $55^{\circ} \mathrm{N}$ and $60^{\circ}$ and $135^{\circ} \mathrm{E}$ (Fig. 1a). This region was represented by a $0.5^{\circ} \times 0.5^{\circ}$ grid in latitude and longitude, with a total of 9978 grid boxes.

\section{a. Instrumental data}

To both calibrate the proxy data to form a reconstruction and validate that reconstruction, we made use of gridded monthly instrumental precipitation data over the interval 1900-2008 developed by Legates and Willmott (1990). This dataset merged several updated gauge observations of precipitation and interpolated them to grid points covering the global land areas at $0.5^{\circ} \times 0.5^{\circ}$ resolution in latitude and longitude. The spatial interpolation was based on the spherical implementation of Shepard's spatial interpolation algorithms and also 
incorporated digital elevation model-assisted and climatologically aided interpolation methods (Legates and Willmott 1990).

The period 1950-99 was used for calibration, and the period 1930-49 was reserved for verification. This choice is motivated by the fact that there are fewer stations with precipitation data for the early half of the twentieth century. With the exception of India, the majority of stations in our study region initiated instrumental measurements in the 1950s (Feng et al. 2004; Chen et al. 2011; Fang et al. 2011). It was thus preferable for the calibration to be performed over the more data-rich post-1950 time interval, though this choice imposes restrictions in some cases on the validation exercises. Nonetheless, all other things being equal, a more robust calibration yields a higher-quality reconstruction.

\section{b. Proxy data}

We compiled a dataset of 284 proxy records with annual resolution available within our target reconstruction domain. These records included tree-ring and ice core data, as well as dryness/wetness intensity estimates derived from ancient Chinese documentary records. A few long-term instrumental precipitation measurements at sites in India (Sontakke et al. 2008) back to 1813 and South Korea back to 1770 also were used in the reconstruction. The tree-ring chronologies were taken from the International Tree-Ring Data Bank (http:// www.ncdc.noaa.gov/paleo/treering.html) and the Chinese Tree-Ring Data Center (http://ctrdb.ibcas.ac.cn/index. asp), combined with other published tree-ring chronologies (e.g., Yuan et al. 2003; Q.-B. Zhang et al. 2003). In a few cases, the tree-ring precipitation reconstructions were used where the original tree-ring chronologies themselves are unavailable. The ice core data were taken from three sites in the Tibetan Plateau (Yao et al. 1996; Wang et al. 2007).

While it is debatable whether the long-term instrumental precipitation measurements in India and South Korea should be used in reconstructions, we believe that, for the sake of providing information on precipitation for reconstructions, the Indian or the Korean long instrumental record series were similar to the tree rings and other proxies. In fact, many tree-ring records available in our study region and those used in some prior reconstructions (e.g., Fang et al. 2011) have their record lengths comparable to those of the Indian or Korean record lengths (back to 1813 and 1770, respectively). Deriving the precipitation information from those tree-ring records or using the precipitation information directly from the long-term records of precipitation should serve the same purpose in the reconstructions. The information from the long-term instrumental measurement series in India and South Korea could contribute to details in the reconstructions inside those regions. This concept was tested and shown useful in previous precipitation reconstructions in regions of Europe and southern South America (Pauling et al. 2006; Neukom et al. 2010).

The Chinese documentary data were obtained from the yearly charts of dryness/wetness in China for the last 500 years (Central Meteorological Bureau 1981). These dryness/wetness data were derived on the basis of written descriptions of the past dry/wet conditions in local gazettes and other historical writings. These writings were scrutinized for accuracy and consistency and then transformed into a quantitative dryness/wetness index (DWI). The DWIs at each station take on ordinal values of $1,2,3,4$, or 5 to represent very wet, wet, normal, dry, and very dry conditions, respectively. When instrumental observations became available at a given site/station after 1950, the observed boreal warm season (May-September) precipitation totals were transformed to DWI values using the same numerical scale, assuming the distribution of the relative frequencies of the five grades to be constant (Central Meteorological Bureau 1981; Zhang and Crowley 1989). The validity of this assumption has been examined and established for individual sites (Yao 1982; Ronberg and Wang 1987). The series were extended through 1999 on the basis of more recent instrumental precipitation data (Qian et al. 2003; D. Zhang et al. 2003). Details of the procedures are documented in D. Zhang et al. (2003) and Zhang and Crowley (1989). Because the documentary records in western China are short (they go back only a century), we only used the documentary data in eastern China in our reconstruction.

There is an additional matter related to the combined use of Chinese documentary data and the appropriately discretized modern instrumental data that warrants some discussion. Ideally, the documentary data would overlap in time with the early instrumental period, so that the DWI estimates derived from the former could be validated by the latter. Such an overlap, unfortunately, does not exist (Central Meteorological Bureau 1981). The DWI estimates during 1951-99 were derived exclusively from the instrumental precipitation data. For stations with limited instrumental data before 1950, their DWIs also were derived from the available measurements. However, how much of the pre-1950 documentary data were derived with aid from the graded instrumental precipitation data was not available in the original documents (Central Meteorological Bureau 1981; D. Zhang et al. 2003). Thus, the DWI estimates potentially have additional uncertainty and possible biases because of changes in qualitative interpretation over time. Jones et al. (2003) and Jones (2008) argue that the documentary 
data are likely to be markedly lower in quality during the earlier years. On the other hand, the DWI estimates have been found to be consistent with precipitation reconstructions from tree rings and speleothems in China (e.g., Zhang et al. 2008; Tan et al. 2011; Yi et al. 2012), suggesting that the documentary data are in fact of sufficient quality for use in paleoclimate reconstruction.

Different types of proxy records have different sensitivities to precipitation and its seasonal variation. For example, the DWI data in China described the variations in May-September precipitation (Central Meteorological Bureau 1981), and the ice core data recorded the snow accumulation at high elevations primarily during the rainy season (Yao et al. 1996; Wang et al. 2007). Both the documentary and ice core data recorded the precipitation variations. The tree-ring data, however, registered the growing season conditions from essentially May to September in the Northern Hemisphere and contained both precipitation and temperature information.

To select the tree-ring records that are sensitive to the precipitation in May-September, which covers the major monsoon and growing season in Asia, we correlated the tree-ring records at individual sites with the gridded precipitation data for 1950-2008 developed by Legates and Willmott (1990). The proxy records that exhibited strong correlations at $p<0.05$ with precipitation from at least one of the grid points in the study region were retained. We used this criterion because the reconstruction method used in this study, discussed in the next section, does not require the proxy records to be correlated with local precipitation (Zhang et al. 2004; Neukom et al. 2010, 2011). We also removed the treering records that started after 1850 .

After applying the above procedures to sift the proxy records at all the sites, we obtained 207 proxy record series in the study region. Of the 207 series were 101 tree-ring-width or tree-ring-based precipitation reconstructions, 103 documentary data, and 3 ice core data series. With seven long-term instrumental records in India and one in South Korea (Seoul), we have a total of 215 record time series. These series will be referred to as "proxy records" in the following discussion. The spatial locations of the record sites are shown in Fig. 1a, which indicate relatively dense proxy records in the eastern half of China, northern Mongolia, and the regions south of the Himalayas and sparse records in central, southern, and southeastern Asia.

As shown in Fig. 1b, the number of available proxies decreased back in time, as anticipated. Most of these records have a time length between 200 and 500 years, except for a few tree-ring records in the northern Tibetan Plateau dating back to over 1000 years ago. The number of proxy records increased substantially since 1470 with the addition of the Chinese documentary records. The proxy records also have different ending years, and only a few of the records last through 2000. These available records warrant a reconstruction of May-September precipitation from 1470 to 1999.

For missing values of the proxy records at individual sites during this reconstruction period, we estimated them using the analog technique described in Guiot et al. (2005). Using the estimated values, we eliminate changes in variance caused by decreasing numbers of available proxies back in time, albeit on the basis of assumptions of stationarity implicit in the analog technique.

\section{c. Reconstruction method}

We used the Regularized Expectation Maximization (RegEM) method for climate field reconstruction (Schneider 2001; Mann and Rutherford 2002; Rutherford et al. 2005; Mann et al. 2007) in this study. This method has been tested with synthetic pseudoproxy data (e.g., Mann and Rutherford 2002; Mann et al. 2007) and been used frequently over the past decade for the problem of proxy-based paleoclimate reconstruction (e.g., Zhang et al. 2004; Rutherford et al. 2005; Mann et al. 2008, 2009; Riedwyl et al. 2009; Neukom et al. 2011; Pauling et al. 2006; Smerdon et al. 2011). Zhang et al. (2004) showed that RegEM can modestly improve the reconstruction skill for large-scale drought reconstruction (in North America) relative to the alternative point-by-point regression (PPR) technique (Cook et al. 1999, 2004). These past findings motivate our present methodological choice of RegEM for reconstructing large-scale precipitation over the Asian continent.

As in the PPR method (Cook et al. 2010), the RegEM also makes use of nonlocal relationships and large-scale covariance information between the instrumental data and the proxy records to reconstruct past climate. Zhang et al. (2004) suggested that RegEM, through use of teleconnection relationships between predictors and predictands, is particularly useful in reconstructing drought patterns with sparse proxy data. This property of RegEM is amenable to our study because of the highly heterogeneous distribution of the proxy data available in the reconstruction region (Fig. 1a). While early implementation of RegEM for climate field reconstruction made use of ridge regression for regularization (Schneider 2001; Mann and Rutherford 2002; Rutherford et al. 2005), more recent tests with synthetic pseudoproxy networks show that an alternative regularization scheme based on truncated total least squares (TTLS) regression leads to a more faithful reconstruction of low-frequency variability (Mann et al. 2007, 2008). 
To use RegEM with the TTLS algorithm, we first constructed the empirical orthogonal function (EOF) and associated principal components (PCs) of the observed May-September precipitation from 1950 to 1999. We then applied RegEM to the proxy data and projected the PCs of the observed data back to 1470 . The precipitation of the targeted years was reconstructed by a reverse transformation of the PCs and the EOFs into precipitation at each grid point (Rutherford et al. 2005; Mann et al. 2007), under the implicit assumption that past precipitation changes can be spanned by similar eigenfunctions to those of the modern interval. This assumption appears to hold in tests with synthetic pseudoproxy data derived from long-term climate model simulations (see Mann et al. 2007).

In contrast to temperature reconstruction, a challenge for using RegEM in precipitation reconstruction is that the precipitation is highly variable in space, especially across complex terrains, such as in our study region. For example, the May-September precipitation in the southeastern Tibetan Plateau is larger than $3000 \mathrm{~mm}$, but in Tarim River basin, west of the plateau, the precipitation is only a few tens of millimeters for those months. In such situations, a few leading EOFs of the entire study region may only explain a small portion of the total precipitation variance in the region. Although retaining more EOFs would keep more variance, the additional EOFs also bring more noise to the problem because they only explain a very small portion (usually less than $3 \%$ ) of the total variance. When using RegEM to reconstruct the summer drought patterns in the United States, Zhang et al. (2004) tested three distinctive calibration schemes. They found that the cross-validated skill of the reconstructed Palmer drought severity index (PDSI) was the highest if the PDSI was first reconstructed in eight subregions and then merged together to form the reconstruction for the entire contiguous United States. The results of Zhang et al. prompted us to apply a similar approach to meet the challenge and use RegEM in our reconstruction of precipitation over a large domain with complex terrains. Accordingly, we divided our region into smaller subregions that have relatively homogeneous topography so that the difficulty for applying RegEM to precipitation reconstruction could be reduced. Specifically, we first divided the study region into $10^{\circ}$ latitude $\times 10^{\circ}$ longitude boxes and reconstructed the precipitation for each box. If the verification skill (measured by the reduction of error RE) is low (e.g., $\mathrm{RE}<0$ for more than $20 \%$ of the grid points) for a given box, the box was further divided into smaller boxes. As a result of this trial-and-error process, we divided our study region into 44 subregions (Fig. 1a) and used RegEM with TTLS to reconstruct MaySeptember precipitation in each subregion.
As shown in Fig. 1a, among the 44 subregions, some (except for subregions over oceans) have no proxy sites, for example, subregions 17 and 18. For those subregions, proxy records outside the target subregions were used. For subregions containing proxy sites, proxy records outside the subregions also were used in the reconstruction. The proxy records outside a subregion were selected according to their correlation with the precipitation inside the subregion. Including these teleconnection effects would not only allow for reconstructing precipitation in subregions without proxy records but also improve the reconstruction for subregions with proxy records (Zhang et al. 2004; Neukom et al. 2010, 2011).

To identify the remote proxy records influencing the precipitation of each subregion, we first calculated the correlations between each of the 215 proxy records and the observed precipitation at each grid point inside the target subregion during 1950-99. The proxy records with significant correlations at $p<0.10$ with at least $10 \%$ of the grid points inside the target subregion were selected as the remote proxy records and used in the reconstruction for the target subregion. The significance threshold $p<0.10$ was used to select the predictors because it yielded better reconstruction results than the $p<0.05$ threshold. From this procedure, we identified between 99 and 197 proxy records for the subregions.

The reconstruction skill was measured by the square of correlation $R^{2}$ between the reconstructed values and the corresponding observations during the verification period from 1930 to 1949. The RE and coefficient of efficiency (CE) statistics were also computed. The RE and CE have been frequently used in previous studies to evaluate reconstruction skills (e.g., Cook et al. 1994; Mann et al. 2008; Rutherford et al. 2005; Pauling et al. 2006). Following Cook et al. (1994), $\mathrm{RE}=1.0-\left\{\left[\sum\left(x_{i}-\hat{x}_{i}\right)^{2}\right] /\left[\sum\left(x_{i}-\bar{x}_{c}\right)^{2}\right]\right\}$ and $\mathrm{CE}=1.0-\left\{\left[\sum\left(x_{i}-\hat{x}_{i}\right)^{2}\right] /\left[\sum\left(x_{i}-\bar{x}_{v}\right)^{2}\right]\right\}$, where $\bar{x}_{c}$ and $\bar{x}_{v}$ are the mean of the observations during the calibration and verification period, respectively, and $x_{i}$ and $\hat{x}_{i}$ are the observed and reconstructed values during the verification period, respectively. The value $R E=1$ indicates no difference between the reconstruction and the observation during the verification period and is thus a perfect reconstruction. The value $\mathrm{RE}=0$ suggests that the reconstruction is no better than the climatology of the calibration period, and RE $<0$ suggests the reconstruction is worse than simply using the mean values of the calibration period. Therefore, $\mathrm{RE}>0$ has been the criterion for skillful reconstruction. The $\mathrm{CE}$ is similar to the $\mathrm{RE}$ and ranges from $-\infty$ to 1.0 , with $\mathrm{CE}=0$ being no better than the climatology of the verification period, that is, $\bar{x}_{v}$. The value $\mathrm{CE}>0$ indicates useful skill in the 

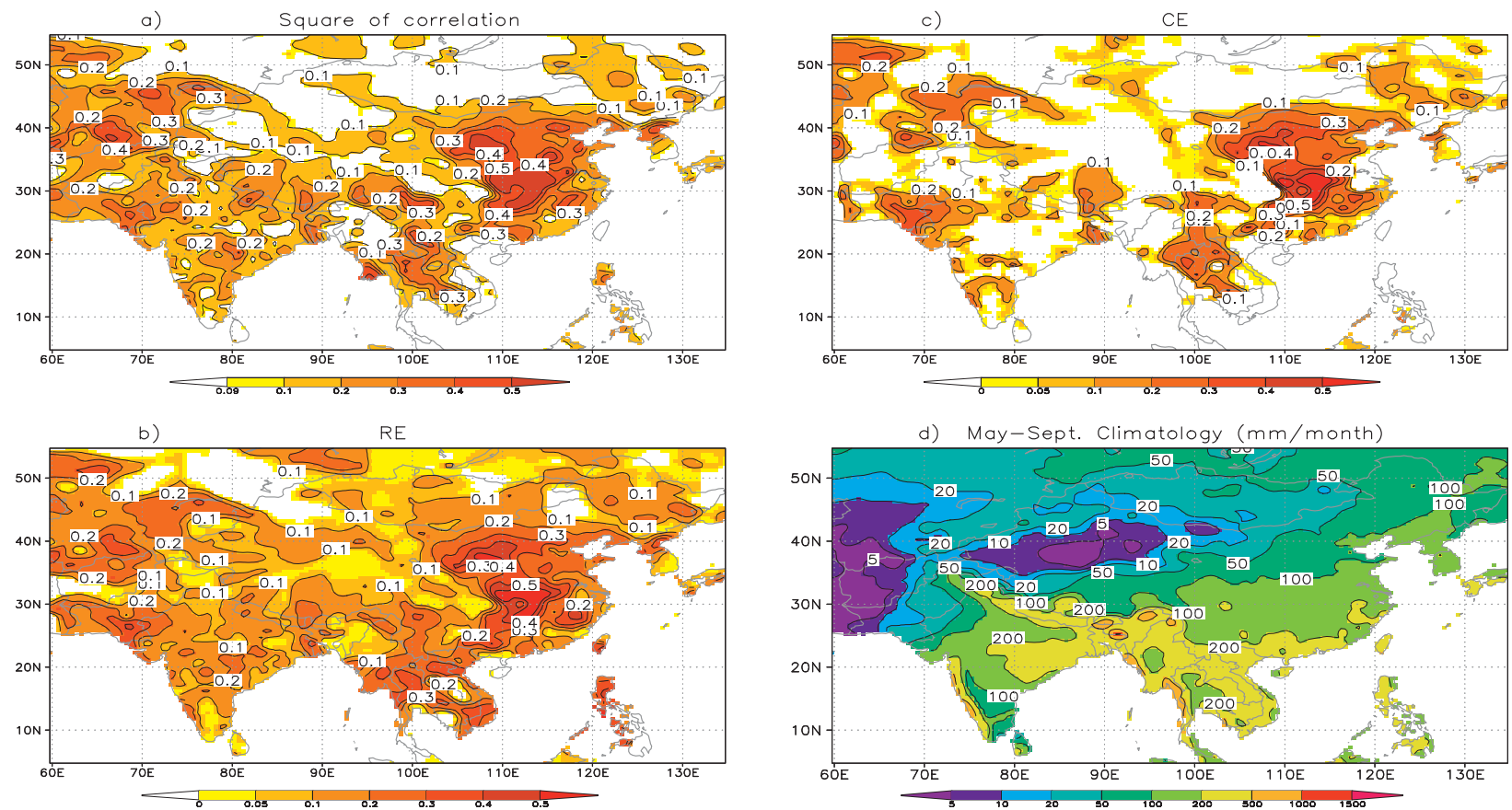

FIG. 2. (a) Spatial distribution of the $R^{2}$ between the reconstructed and observed May-September precipitation. Only those grid points with $R^{2}$ higher than the one-tailed 90\% level were shown. (b) RE distribution during 1930-49. The regions with skill reconstruction (RE $>0$ ) were shown. (c) CE distribution. (d) Spatial distribution of the mean May-September precipitation from observations of 1950 to 99 .

reconstruction. The $\mathrm{CE}$ is always smaller than the $\mathrm{RE}$ when $\bar{x}_{c} \neq \bar{x}_{v}$. When $\bar{x}_{c}=\bar{x}_{v}$, CE equals RE (Cook et al. 2010). Hence, the CE is a more strict statistic and leads to fewer regions passing the $\mathrm{CE}>0$ skillful criterion.

The reconstruction skill was further examined by comparing the spatial patterns of the observed and the reconstructed precipitation during the verification period, using the spatial RE and spatial correlation SC described in Zhang et al. (2004):

$$
\text { Spatial } \mathrm{RE}_{i}=\left[\sum_{j}\left(x_{i j}-\hat{x}_{i j}\right)^{2}\right] /\left[\sum_{j}\left(x_{i j}-\bar{x}_{j c}\right)^{2}\right]
$$

In the above, $x_{i j}$ and $\hat{x}_{i j}$ are the observed and reconstructed May-September precipitation for year $i$ at grid point $j ; \bar{x}_{j c}$ is the mean observed precipitation at grid point $j$ during the calibration period; $x n_{i j}$ and $\widehat{x n}_{i j}$ are the normalized observed and reconstructed May-September precipitation for year $i$ at grid point $j$ based on the means and standard deviation of the calibration period; and $\overline{x n}_{i}$ and $\widehat{\overline{x n}}_{i}$ are the means of observed and reconstructed values for each grid point in year $i$, respectively. The observed and reconstructed precipitations were normalized before computing their spatial correlations to avoid possible bias related to the variances of the precipitation (Zhang et al. 2004).

\section{Evaluations of the reconstructed precipitation}

\section{a. Verification of the reconstruction}

Figure 2a shows the $R^{2}$ between the reconstructed and observed May-September precipitation in our study region for the verification period 1930-49. As in Cook et al. (2010), we only plot those grid points that the $R^{2}$ is higher than the one-tailed $90 \%$ level. The $R^{2}$ shows considerable spatial variability. Significant $R^{2}(p<0.10$, one tail) is shown in majority of the study regions, especially in eastern China and central, southwestern, and southeastern Asia. The $R^{2}$ is weak and insignificant over Mongolia, northwestern China, and the northern part of 
TABLE 1. Verification scores for two regions (defined in section 3b) during 1930-49. The last column shows the correlations between our reconstructed precipitation and those reconstructed in previous studies for the noted periods in the parentheses.

\begin{tabular}{ccccc}
\hline \hline Regions & $R^{2}$ & $\mathrm{CE}$ & $\mathrm{RE}$ & $\begin{array}{c}\text { Correlation with } \\
\text { previous reconstruction }\end{array}$ \\
\hline $\begin{array}{c}\text { North-central } \\
\text { China }\end{array}$ & 0.617 & 0.504 & 0.525 & $0.751(1470-1949)$ \\
$\begin{array}{c}\text { Northwest } \\
\text { China }\end{array}$ & 0.435 & 0.420 & 0.436 & $0.280(1800-1949)$ \\
\hline
\end{tabular}

central Asia. Meanwhile, the RE in Fig. $2 b$ is positive in $90.2 \%$ of the study region, indicating skillful reconstructions. Areas of high reconstruction skills (RE $>$ $0.3)$ are in eastern China and parts of central and southeastern Asia. The more rigorous statistic, CE, shows similar spatial patterns of skill, except that the magnitudes of skill are lower than that for RE. These testing results indicate significant reconstruction skills in eastern China and parts of the Indian subcontinent, suggesting that our reconstructions are useful for studies of the Asian summer monsoon variability in the past 530 years. The areas with poor reconstruction skill $(\mathrm{RE}<0$ and $\mathrm{CE}<0)$ are mainly located in the semiarid and arid areas where the summertime precipitation is less than $50 \mathrm{~mm} \mathrm{month}^{-1}$ (Fig. 2d). Those areas have very few observations, especially before the 1950s (Chen et al. 2011; Fang et al. 2011; Cook et al. 2010), and also have limited proxy records for reconstruction (comparing Figs. $2 \mathrm{~d}$ and 1a). Many of the gridded precipitation data before 1950 in those regions were actually estimated by interpolating the observations at stations several hundreds of kilometers away from the grids. Such interpolation may cause inconsistences between the interpolated (observed) precipitation and reconstructed precipitation, therefore lowering the reconstruction skill. In addition, large variability of the warm season precipitation in the arid and semiarid areas makes it difficult to get skillful precipitation reconstructions. Similar difficulties were also encountered in reconstructing precipitation in the arid regions in southern South America (Neukom et al. 2010).

Despite the relatively low reconstruction skills in the semiarid and arid areas, the precipitation averaged in those areas was in fairly good agreement with the observations. For instance, while $\mathrm{CE}<0, \mathrm{RE}<0.1$, and $R^{2}$ is insignificant in most of the northwestern China, the average precipitation reconstructed for that area is similar to the average calculated from available local observations (Table 1). The $R^{2}$ between the reconstructed and observed precipitation during the verification period is $0.435(p<0.05)$, and the RE and $\mathrm{CE}$
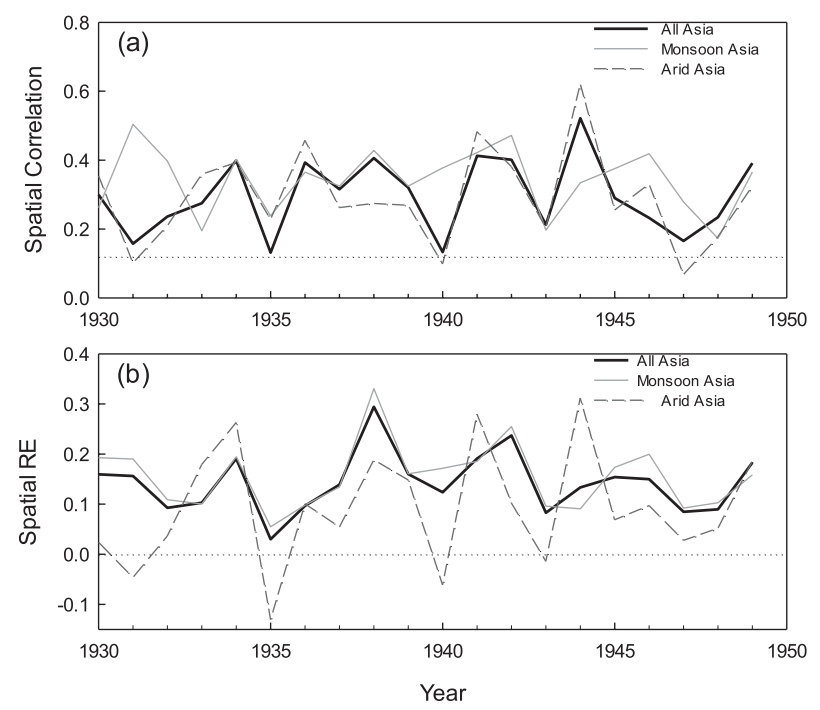

FIG. 3. (a) Temporal variations of pattern correlation between the reconstructed and observed May-September precipitation anomalies in different regions and (b) spatial RE for all Asia, monsoon Asia, and arid Asia during 1930-49. These two statistics quantify the degree of similarity between the observed and reconstructed May-September precipitation patterns over the years.

are both larger than 0.4. Similar results also were observed in north-central China (Table 1). A possible mechanism for higher reconstruction skill on regional average than at individual grids could be that the local land cover and topography can strongly influence local precipitation. Such local effects on precipitation are difficult to be reconstructed. When the precipitations are averaged, such local effects at individual grids are smoothed out or weakened substantially while the largescale climate signals become outstanding. These results also suggest that, although the reconstruction skill may be low in local areas of semiarid or arid climate, our reconstructions were reliable in depicting regional precipitation. Nonetheless, the low reconstruction skills in the semiarid and arid areas raise cautions for interpreting local precipitation in those areas.

The reconstruction skill was further examined by comparing the temporal homogeneity between the observed and reconstructed precipitation patterns using the spatial RE and SC outlined in Eqs. (1) and (2). Because the arid and semiarid areas have poorer reconstruction skills than the wet climate areas, for example, the Asian summer monsoon regions, we examined temporal homogeneity separately for those different areas. The results are shown in Fig. 3 for the verification period. The spatial correlations between the observed and the reconstructed precipitation for the entire reconstruction region (all Asia) and wet areas (monsoon Asia) are all significant at $p<0.05$ for all 
years in the verification period. The spatial correlation for the arid and semiarid areas (arid Asia) are also significant at $p<0.05$, except for 1931,1940, and 1947. The spatial correlation for monsoon Asia is generally higher than that for arid Asia and all Asia. The mean spatial correlations for the verification period are 0.300, 0.290, and 0.340 for all, arid, and monsoon Asia, respectively. Additionally, the spatial correlation for arid Asia was steadily increasing during the verification period, possibly attributable to increasing observations in the same period.

The spatial variations of RE shown in Fig. 3b indicate that the mean spatial RE for the verification period is 0.16 and 0.14 for monsoon Asia and all Asia, respectively. The spatial RE for arid Asia is slightly lower. There were four years, 1931, 1935, 1940, and 1943, with spatial RE slightly lower than zero in arid Asia. As in the spatial correlation, the reconstruction skills for arid Asia were improved in the 1940s, again attributable to an increasing number of observations in that decade.

\section{b. Comparisons with previous reconstructions}

As an additional evaluation of our reconstructions, we compared them with previous precipitation reconstructions that fall within our study region. For example, Yi et al. (2012) reconstructed June-August precipitation in north-central China $\left(33^{\circ}-41^{\circ} \mathrm{N}, 108^{\circ}-\right.$ $115^{\circ} \mathrm{E}$ ) using tree-ring and documentary data and a stepwise regression method. Figure 4a shows a comparison of our reconstructed precipitation with theirs averaged over the same area. The interannual and decadal variations of the two reconstructions are very similar during the past 530 years, with the correlation coefficient at 0.751 . Because the two reconstructions were based on different methods (RegEM versus stepwise regression) and also months of the year (MaySeptember versus June-August) these similarities suggest that both reconstructions captured the precipitation signals in north-central China. The major dry periods in 1481-87, 1586-89, 1637-43, 1876-78, and 1928-31 that were revealed in historical documentaries are described in both reconstructions.

In a recent study, Fang et al. (2011) reconstructed the January-October precipitation for 1800-2000 at 26 sites in northwestern China using 132 tree-ring series and the PPR method. Ten of their 132 chronologies were also used in this study. Thus, our reconstruction also has a little overlap of data sources with Fang et al.'s. A comparison of our reconstruction and theirs is shown in Fig. 4b. We note that, because the major rainy season in northwestern China is from May to September, the mean monthly precipitation averaged over the months from January to October is smaller than that averaged
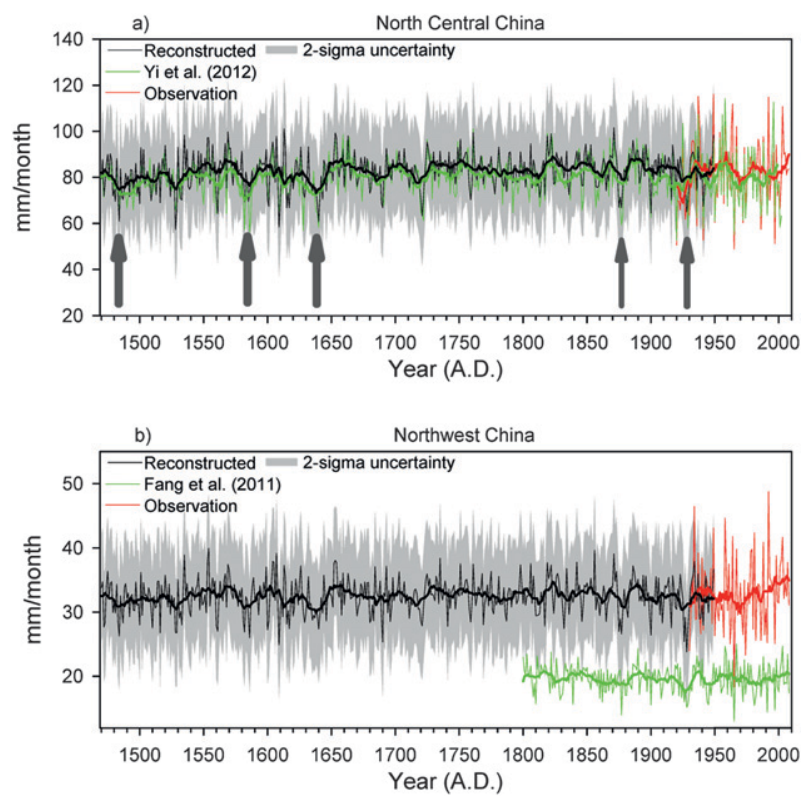

FIG. 4. Comparisons between our reconstructed precipitation and that reconstructed by (a) Yi et al. (2012) for north-central China and (b) Fang et al. (2011) for northwestern China. The gray bars show the 2- $\sigma$ uncertainty of our reconstructed precipitation, and the thicker lines show the 9-yr smoothing. The large arrows in (a) highlight the five severe droughts.

from May to September. With this in mind, the comparison in Fig. 4b shows similar variations in 1800-1999, despite the differences in proxy records and methods used in these two reconstructions. Several particularly dry periods in the 1870 s and from the late 1920 s to the early 1930s, as well as the wet periods in the 1880s and late 1930s, were captured by both reconstructions. The correlation coefficient between the two reconstructions is at $0.280(p<0.05)$ during $1800-1949$. The disagreement between the two reconstructions in the 1940s, 1810 s, and 1820 s could be attributed partially to the seasonal difference in the two reconstructions.

To summarize, these consistent results from comparisons between our reconstruction and the previous reconstructions in some subregions of our reconstruction domain and within our time period have provided strong support to our reconstruction skills for Asian precipitation.

\section{Reconstructed dataset and examples of data use}

After careful examination and evaluation of the reconstruction procedures and skills, we have produced a reconstructed gridded dataset of May-September precipitation from 1470 to 1999 for Asia $\left(5^{\circ}-55^{\circ} \mathrm{N}, 60^{\circ}-135^{\circ} \mathrm{E}\right)$. This new dataset allows us to analyze precipitation 

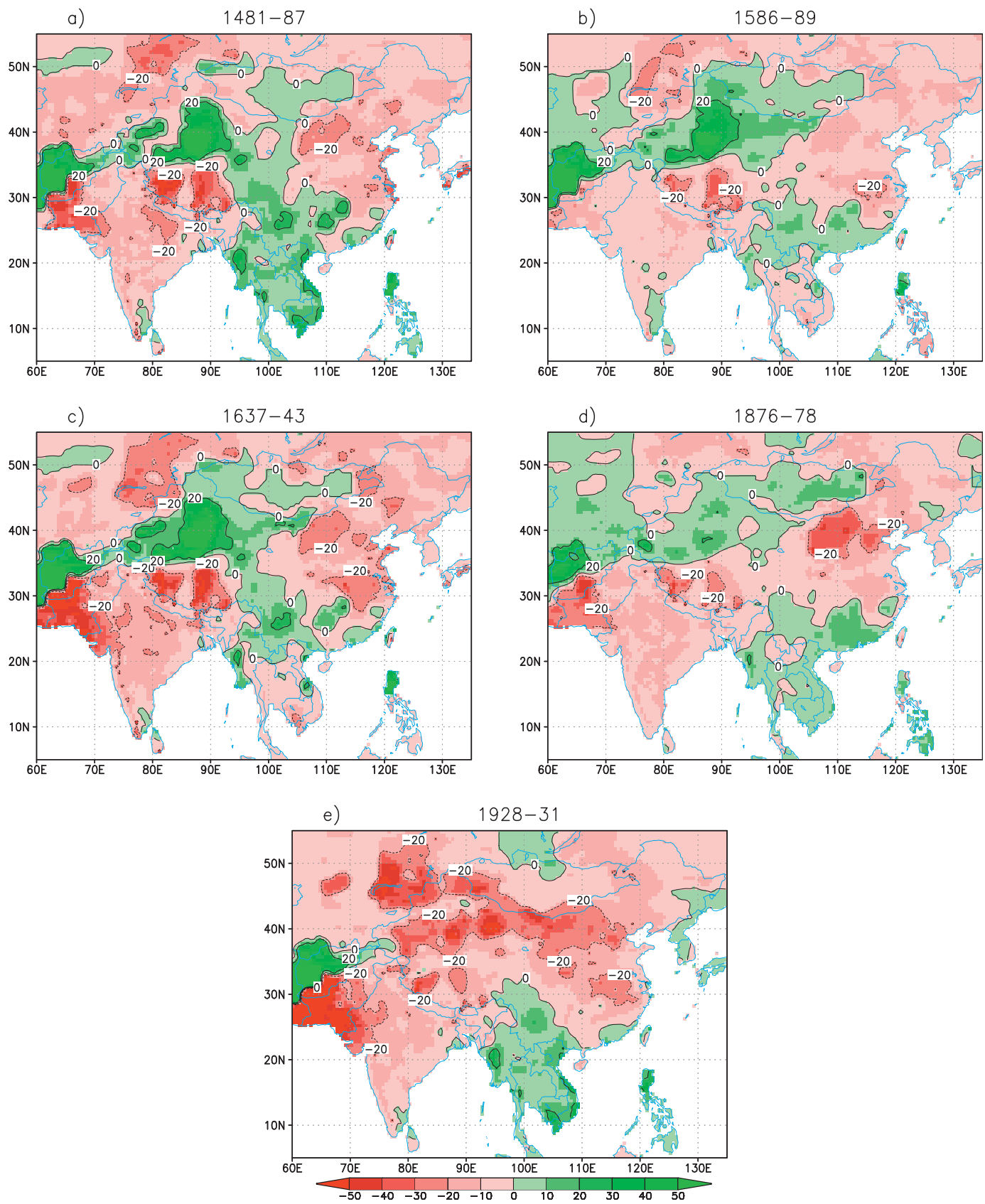

FIG. 5. (a)-(e) Spatial patterns of the percentage of anomalies of reconstructed May-September precipitation relative to the 1950-99 climatological mean during the five severe droughts in north-central China.

variations in the study region and floods and droughts over the past 530 years.

To illustrate the utility of this dataset in describing large-scale precipitation variations in the past, we examined the reconstructed precipitation for the regional pattern and severity of five well-documented historical droughts in north-central China in 1481-87, 1586-89, 1637-43, 1876-78, and 1928-31.
These events are clearly indicated in the time series of Fig. 4a. As shown in Fig. 4a, there was a dry period in north-central China lasting about 20 years in the late fifteenth century. The most severe drought occurred from 1481 to 1487 . This drought also was reported in Qian et al. (2003). The spatial pattern of the averaged May-September precipitation anomalies for 1481-87, relative to the mean of $1950-99$, is shown in Fig. 5a. A 
majority of northern and eastern China was dry. In north-central China and the middle and lower reaches of the Yangtze River (MLRYR), precipitation was 20\% below the 1950-99 average.

Another severe drought event occurred in northcentral China from 1586 to 1589 , most severe in 1589 (Figs. 4a, 5b). Chinese documentary records (Shen et al. 2007) showed that the drought occurred in northern China in 1586 and 1587. The center of the drought migrated to the MLRYR in 1589 while drought spread over $48 \%$ of eastern China. The spatial pattern of this drought is shown in Fig. 5b, indicating a $10 \%-20 \%$ precipitation reduction in the MLRYR and northcentral China from the average.

The well-documented late Ming dynasty drought from 1637 to 1643 appeared in some historical records as the most severe drought in China over the past five centuries (Shen et al. 2007). Some studies (Shen et al. 2007; Zhang et al. 2008) suggested that this severe drought triggered the collapse of the Ming dynasty. Our reconstruction (Figs. 4a, 5c) shows that, except for a small portion in south and southwest China, eastern China (east of $105^{\circ} \mathrm{E}$ ) received less than $10 \%$ of the average precipitation during that period. The most severe rainfall deficit occurred in north-central China and MLRYR, where rebellions rose, weakened, and could have eventually brought down the Ming dynasty. While the pattern of drought in Fig. $5 c$ is consistent with the regional averaged dry/wet variations in eastern China reported in Shen et al. (2007), it provides more detailed spatial variations of the drought and its intensity.

A more recent severe drought occurred in 1876-78, concurring with one of the strongest El Niño events of the past 150 years (Davis 2001). The effects of this devastating drought were felt across much of the tropical regions, particularly in India; more than 30 million people perished because of famines and diseases induced by the widespread droughts (Davis 2001). Our reconstructed precipitation shown in Fig. 5d indicates that the entirety of India and a majority of Pakistan had severe precipitation deficit. The drought was more severe in north-central China, however, where $20 \%-30 \%$ precipitation deficit occurred.

Another very severe drought that persisted from 1928 to 1931 was also captured in our reconstructed MaySeptember precipitation (Fig. 5e). During those drought years, warm season precipitation in north-central China was only about $50 \%$ of the average amount. Subsequent famines and related diseases claimed more than 4 million lives in northern China (Liang et al. 2006). The drought also extended to MLRYR and resulted in more than $20 \%$ reduction of precipitation from the average. Meanwhile, droughts of similar intensity occurred in northwest China, Pakistan, and India. In terms of severity and the areal extent, this drought was the most extreme of the past 500 years in the standard of this reconstruction.

These major droughts, except for the one in 1481-87, were also described by the PDSI reconstructed from treering chronologies by Cook et al. (2010). For 1481-87, their reconstructed PDSI suggested a moderate wet period in north-central China and India. This result is different from the finding of a weaker summer monsoon in the sediment data in the Arabian Sea and Oman (Sinha et al. 2011) and dry conditions in north-central China revealed in speleothem records (e.g., Zhang et al. 2008; Tan et al. 2011). This difference in the PDSI results could be from the impact of temperature and soil characteristics on the PDSI reconstruction. Additionally, while the severe drought in north China, India, and Pakistan in 1876-78 was shown in our reconstruction and also in the reconstructed PDSI by Cook et al. (2010), the two reconstructions show different conditions in southeastern Asia. The reconstructed PDSI suggests a rather dry condition in that region in 1876-78, a result also supported by local historical references (Davis 2001). Our reconstructed precipitation, however, indicates above-average rainfall in that area during those summers (Fig. 5d). These opposite results could again be attributed to the differences between precipitation and the PDSI, which contains information of temperature and soil water effect, and the differences in methods used in the reconstructions.

In addition to describing these severe climate events, our reconstructed gridded precipitation dataset provides insight on interrelationships or patterns of the warm season precipitation variation in the study region. Several distinctive patterns from the five panels in Fig. 5 may be summarized as follows:

1) Similar anomalies in May-September precipitation (e.g., drought) developed in northeastern China, north-central Asia $\left(45^{\circ}-55^{\circ} \mathrm{N}, 65^{\circ}-95^{\circ} \mathrm{E}\right)$, India, and Pakistan. Concurrently, opposite anomalies in precipitation persisted in arid central Asia, including the southern Xinjiang Uygur autonomous region of China (approximately $35^{\circ}-42^{\circ} \mathrm{N}, 60^{\circ}-95^{\circ} \mathrm{E}$ ).

2) In eastern China, east of $100^{\circ} \mathrm{E}$, May-September precipitation anomalies were opposite between the north and the south $\left(20^{\circ}-27^{\circ} \mathrm{N}, 100^{\circ}-122^{\circ} \mathrm{E}\right)$. While a similar finding was shown in the instrumental records in recent decades in Hu and Feng (2001), our results suggested that this dipolar precipitation anomaly pattern in eastern China was persistent in the last 530 years.

3) The opposite precipitation anomaly pattern between northern China and the arid central Asia and south 
Xinjiang Uygur in China also was identified by instrumental data (Chen et al. 2011) and by proxy records on decadal and centennial time scales (Chen et al. 2010; Fang et al. 2010). Our results further suggest that a similar pattern persisted on interannual to decadal time scales in the past half millennium.

Finally, the similar large-scale spatial patterns of the precipitation anomalies during the five most severe droughts in north-central China, India, and Pakistan in the past half millennium (Fig. 5) suggest that these severe droughts might have been driven by the same set of forcings. Because the droughts in 1876-78 were likely an indication of the failure of the Indian summer monsoon during a strong El Niño (Davis 2001), the sea surface temperature (SST) anomalies in the eastern tropical Pacific associated with the El Niño-Southern Oscillation (ENSO) (e.g., Webster et al. 1998; Feng and Hu 2004; Cook et al. 2010), as well as the SST anomalies in the North Atlantic (e.g., Feng and $\mathrm{Hu}$ 2008; Berkelhammer et al. 2010), could have played important roles in driving such anomaly patterns of precipitation in Asia. This speculation deserves further investigation, and this dataset provides the needed information for such explorations.

\section{Conclusions}

In this study, we reconstructed gridded $\left(0.5^{\circ} \times 0.5^{\circ}\right.$ resolution in latitude and longitude) May-September mean precipitation for Asia (terrestrial areas in $5^{\circ}-55^{\circ} \mathrm{N}$ and $60^{\circ}-135^{\circ} \mathrm{E}$ ) back to the late fifteenth century using the RegEM climate field reconstruction method and multiproxy and historical predictors. Our validation results suggest that the precipitation reconstruction has the greatest skill in eastern China and areas of wet or humid climate, where precipitation fluctuations are modest in amplitude and sufficient observations are available to both calibrate and validate the reconstruction. Relatively low reconstruction skill, by contrast, is found for arid and semiarid regions of Asia where precipitation fluctuations appear erratic and observational data are scarce. Agreement is relatively good with previous reconstructions where there is spatial and temporal overlap.

The utility of the reconstructed gridded precipitation was demonstrated in a set of examples of five severe and persistent historical droughts that occurred in northcentral China, which are independently reproduced from the reconstructions. The reconstructions provide the larger-term context for understanding the spatial scale, severity, and societal impacts of those droughts, as well as other climate events, and provide insights into the role of larger-scale dynamical mechanisms.

Acknowledgments. We thank Dr. K. Fang of Lanzhou University in China for providing the reconstructed precipitation in northwestern China. Comments and suggestions from three anonymous reviewers helped the clarity of this manuscript and are appreciated. This work has been supported by NOAA Grant NA10OAR4310111 to the University of Nebraska-Lincoln and the Pennsylvania State University (PI: Qi Hu) and by the USDA Cooperative Research Project NEB-38-088. The reconstructions and supplementary materials from this study have been made available at the World Data Center for Paleoclimatology, the paleoclimatology branch of the National Climatic Data Center (NCDC).

\section{REFERENCES}

Berkelhammer, M., A. Sinha, M. Mudelsee, H. Cheng, R. L. Edwards, and K. Cannariato, 2010: Persistent multidecadal power in the Indian summer monsoon. Earth Planet. Sci. Lett., 290, 166-172.

Central Meteorological Bureau, 1981: Atlas of Flood and Drought in China in the Last 500 Years. Cartological Press, $332 \mathrm{pp}$.

Chen, F., and Coauthors, 2010: Moisture changes over the last millennium in arid central Asia: A review, synthesis and comparison with monsoon region. Quat. Sci. Rev., 29, 1055-1068.

_ _ W. Huang, L. Jin, J. Chen, and J. Wang, 2011: Spatiotemporal precipitation variations in the arid central Asia in the context of global warming. Sci. China: Earth Sci., 54, 1812-1821, doi:10.1007/s11430-011-4333-8.

Cook, E. R., K. R. Briffa, and P. D. Jones, 1994: Spatial regression methods in dendroclimatology: A review and comparison of two techniques. Int. J. Climatol., 14, 379-402.

_ D. M. Meko, D. W. Stahle, and M. K. Cleaveland, 1999: Drought reconstructions for the continental United States. J. Climate, 12, 1145-1162.

— C. A. Woodhouse, C. M. Eakin, D. M. Meko, and D. W. Stahle, 2004: Long-term aridity changes in the western United States. Science, 306, 1015-1018.

_ B. M. Anchukaitis, R. D. D'Arrigo, G. C. Jacoby, and W. E. Wright, 2010: Asian monsoon failure and megadrought during the last millennium. Science, 328, 486-489.

Davis, M., 2001: Late Victorian Holocausts: El Niño Famines and the Making of the Third World. Verso, 470 pp.

Fang, K., N. Davi, X. Gou, F. Chen, E. Cook, J. Li, and R. D'Arrigo, 2010: Spatial drought reconstructions for central high Asia based on tree rings. Climate Dyn., 35, 941-951, doi:10.1007/s00382-009-0739-9.

— X. Gou, F. Chen, E. Cook, J. Li, B. Buckley, and R. D'Arrigo, 2011: Large-scale precipitation variability over northwest China inferred from tree rings. J. Climate, 24, 3457-3468.

Feng, S., and Q. Hu, 2004: Variation in teleconnection of ENSO and summer rainfall in northern China: A role of the Indian summer monsoon. J. Climate, 17, 4871-4881.

$\longrightarrow$, and 2008: How the North Atlantic multidecadal oscillation may have influenced the Indian summer monsoon 
during the past two millennia. Geophys. Res. Lett., 35, L01707, doi:10.1029/2007GL032484.

— - _ , and W. Qian, 2004: Quality control of daily meteorological data in China, 1951-2000: A new dataset. Int. J. Climatol., 24, 853-870.

Guiot, J., A. Nicault, C. Rathgeber, J. L. Edouard, F. Guibal, G. Pichard, and C. Till, 2005: Last-millennium summer temperature variations in western Europe based on proxy data Holocene, 15, 489-500.

$\mathrm{Hu}, \mathrm{Q}$., and S. Feng, 2001: Southward migration of centennial-scale variations of drought/flood in eastern China and the western United States. J. Climate, 14, 1323-1328.

Jones, P. D., 2008: Historical climatology-A state of the art review. Weather, 63, 181-186.

_ - K. R. Briffa, and T. J. Osborn, 2003: Changes in the Northern Hemisphere annual cycle: Implications for paleoclimatology? J. Geophys. Res., 108, 4588, doi:10.1029/2003JD003695.

__ , and Coauthors, 2009: High-resolution paleoclimatology of the last millennium: A review of current status and future prospects. Holocene, 19, 3-49.

Legates, D. R., and C. J. Willmott, 1990: Mean seasonal and spatial variability in gauge-corrected, global precipitation. Int. J. Climatol., 10, 111-127.

Liang, E., and Coauthors, 2006: The 1920s drought recorded by tree rings and historical documents in the semi-arid and arid areas of northern China. Climatic Change, 79, 403-432.

Mann, M. E., 2002: The value of multiple proxies. Science, 297, $1481-1482$

—, and S. Rutherford, 2002: Climate reconstruction using 'pseudoproxies.' Geophys. Res. Lett., 29, 1501, doi:10.1029/ 2001 GL014554.

_ - R. S. Bradley, and M. K. Hughes, 1998: Global-scale temperature patterns and climate forcing over the past six centuries. Nature, 392, 779-787.

_ S. Rutherford, E. Wahl, and C. Ammann, 2007: Robustness of proxy-based climate field reconstructions. J. Geophys. Res., 112, D12109, doi:10.1029/2006JD008272.

—, Z. Zhang, M. K. Hughes, R. S. Bradley, S. K. Miller, S. Rutherford, and F. Ni, 2008: Proxy-based reconstructions of hemispheric and global surface temperature variations over the past two millennia. Proc. Natl. Acad. Sci. USA, 105, 13 252-13 257.

_ gins of the Little Ice Age and medieval climate anomaly. Science, 326, 1256-1260.

Neukom, R., and Coauthors, 2010: Multi-centennial summer and winter precipitation variability in southern South America. Geophys. Res. Lett., 37, L14708, doi:10.1029/ 2010GL043680.

_ , and Coauthors, 2011: Multiproxy summer and winter surface air temperature field reconstructions for southern South America covering the past centuries. Climate Dyn., 37, 35-51, doi:10.1007/s00382-010-0793-3.

Pauling, A., J. Luterbacher, C. Casty, and H. Wanner, 2006: Five hundred years of gridded high-resolution precipitation reconstructions over Europe and the connection to large-scale circulation. Climate Dyn., 26, 387-405.

Qian, W. H., Q. Hu, Y. F. Zhu, and D.-K. Lee, 2003: Centennialscale dry-wet variations in east Asia. Climate Dyn., 21, 7789.

Riedwyl, N., M. Küttel, J. Luterbacher, and H. Wanner, 2009: Comparison of climate field reconstruction techniques: Application to Europe. Climate Dyn., 32, 381-395.
Ronberg, B., and W. C. Wang, 1987: Climate patterns derived from Chinese proxy precipitation records: An evaluation of the station networks and statistical techniques. J. Climatol., 7, 391-416.

Rutherford, S., M. E. Mann, T. J. Osborn, K. R. Briffa, P D. Jones, R. S. Bradley, M. K. Hughes, 2005: Proxy-based Northern Hemisphere surface temperature reconstructions: Sensitivity to methodology, predictor network, target season and target domain. J. Climate, 18, 2308-2329.

Schneider, T., 2001: Analysis of incomplete climate data: Estimation of mean values and covariance matrices and imputation of missing values. J. Climate, 14, 853-887.

Shen, C., W.-C. Wang, Z. Hao, and W. Gong, 2007: Exceptional drought events over eastern China during the last five centuries. Climatic Change, 85, 453-471.

Sinha, A., L. Stott, M. Berkelhammer, H. Cheng, R. L. Edwards, B. Buckley, M. Aldenderfer, and M. Mudelsee, 2011: A global context for megadroughts in monsoon Asia during the past millennium. Quat. Sci. Rev., 30, 47-62.

Smerdon, J. E., A. Kaplan, E. Zorita, J. F. González-Rouco, and M. N. Evans, 2011: Spatial performance of four climate field reconstruction methods targeting the Common Era. Geophys. Res. Lett., 38, L11705, doi:10.1029/ 2011GL047372.

Sontakke, N. A., N. Singh, and H. N. Singh, 2008: Instrumental period rainfall series of the Indian region (AD 1813-2005): Revised reconstruction, update and analysis. Holocene, 18, 1055-1066.

Tan, L., Y. Cai, Z. An, R. L. Edwards, H. Cheng, C. C. Shen, and H. Zhang, 2011: Centennial- to decadal-scale monsoon precipitation variability in the semi-humid region, northern China during the last 1860 years: Records from stalagmites in Huangye Cave. Holocene, 21, 287-296.

Touchan, R., E. Xoplaki, G. Funkhouser, J. Luterbacher, M. K. Hughes, N. Erkan, Ü. Akkemik, and J. Stephan, 2005: Reconstructions of spring/summer precipitation for the eastern Mediterranean from tree-ring widths and its connection to large-scael atmospheric circulation. Climate Dyn., 25, $75-98$.

Wang, N. L., X. Jiang, L. G. Thompson, and M. E. Davis, 2007: Accumulation rates over the past 500 years recorded in ice cores from the northern and southern Tibetan Plateau, China. Arct. Antarct. Alp. Res., 39, 671-677.

Webster, P. J., V. O. Magaña, T. N. Palmer, J. Shukla, R. A. Tomas, M. Yanai, and T. Yasunari, 1998: Monsoons: Processes, predictability, and the prospects for prediction. J. Geophys. Res., 103 (C7), 14 451-14 510.

Yao, C. S., 1982: A statistical approach to historical records of flood drought. J. Appl. Meteor., 21, 588-594.

Yao, T., L. G. Thompson, and D. Qin, 1996: Variations in temperature and precipitation in the past 2000 years on the Xizang (Tibet) Plateau-Guliya ice core record. Sci. China, Ser. D: Earth Sci., 39, 425-433.

Yi, L., H. Yu, J. Ge, Z. Lai, X. Xu, L. Qin, and S. Peng, 2012: Reconstructions of annual summer precipitation and temperature in north-central China since 1470 AD based on drought/flood index and tree-ring records. Climatic Change, 110, 469-498.

Yuan, Y., L. Jin, X. Shao, Q. He, Z. Li, and J. Li, 2003: Variations of the spring precipitation day numbers reconstructed from tree rings in the Urumqi River drainage, Tianshan Mts. over the last 370 years. Chin. Sci. Bull., 48, 1507-1510. 
Zhang, D., X. Li, and Y. Liang, 2003: Supplement for "Annals of 510 years of rainfall records in China" (in Chinese). J. Appl. Meteor. Sci., 14, 379-388.

Zhang, J., and T. J. Crowley, 1989: Historical climate records in China and reconstruction of past climates. J. Climate, 2, 833849.

Zhang, P. Z., and Coauthors, 2008: A test of climate, sun, and culture relationships from an 1810-year Chinese cave record. Science, 322, 940-942.
Zhang, Q.-B., G. Cheng, T. Yao, X. Kang, and J. Huang, 2003: A 2,326-year tree-ring record of climate variability on the northeastern Qinghai-Tibetan Plateau. Geophys. Res. Lett., 30, 1739, doi:10.1029/2003GL017425.

Zhang, Z., M. E. Mann, and E. R. Cook, 2004: Alternative methods of proxy-based climate field reconstruction: Application to summer drought over the conterminous United States back to AD 1700 from tree-ring data. Holocene, 14, 502-516. 